\title{
A Study on the Relationship between Tax Compliance and Economic Happiness
}

\author{
Ţibulcă Ioana Laura \\ Bucharest University of Economic Studies, Romania
}

\begin{abstract}
The aim of the current study is to answer the following question: Is tax compliance influenced by the level of happiness people perceive regarding their life? The analysis is based on data regarding the EU Member States. The hypothesis is that people with a higher level of happiness should also have a higher level of tax compliance and, therefore, one measure should be a useful tool in forecasting the other. This hypothesis is tested using Granger causality tests. Quantifying the level of happiness perceived by people living in different countries has been a serious challenge for economists. The current study uses data regarding the perception of happiness from the World Happiness Report for the 28 Member States of the European Union. This report takes many factors into consideration including economic indicators (such as GDP per capita) and social indicators (such as perception of corruption and level of trust in the government). Tax compliance is quantified using the VAT gap as a percentage of VAT total tax liability according to tax law (data provided by Study and Reports on the VAT Gap in the EU-28 Member States: 2018 Final Report). The results show that tax compliance can be used to predict future happiness scores. However, the opposite is not true and happiness scores cannot be used to predict future tax compliance rates.
\end{abstract}

Keywords: Granger causality; living standards; taxation; happiness; 